\title{
Research on the infiltration of moral education in preschool education
}

\author{
Zhu Yan \\ School of preschool education, Longnan Teachers' College , Nantong Vocational University, Longnan, \\ Gansu742500,China \\ yanzhu0689@126.com
}

Keywords: preschool education; moral education; teaching; optimization strategy

\begin{abstract}
Preschool education is very important for a child's growth, which is in the ideological, intellectual enlightenment stage, so a person, a good grasp of the moral education in this period, for the development of children can benefit from life. This paper mainly introduces the implementation of moral education in preschool education, and further analyzes the principle of moral education in the teaching of preschool education, at the end of the article, the author introduces the optimization strategy of preschool education in the teaching of moral education.
\end{abstract}

\section{Significance of carrying out moral education in preschool education}

Many parents want their children to master a lot of knowledge as early as possible, so that they cannot lose at the starting line, which will further lead to kindergarten education into a misunderstanding. Pay too much attention to the training of subject knowledge, lack of ideological education for students, makes some children stubborn personality, not polite, poor psychological ability. Therefore, the lack of family education and the excessive emphasis on knowledge in kindergarten will further lead to imbalance in education.

If you want your child to form a good habit, you are taken small. A person's habits and morals are largely related to his early childhood behavior. So, in this period, for the children for a purpose and a plan for moral education, help children create a virtuous character and personality, so that they are from the urine of Thanksgiving, it is important for a person's education. Preschool education should not only rely on the strength of kindergartens, but also need the influence of the family environment and the children's own efforts, so that they can achieve good results.

From the author's work experience, childhood is a good stage for shaping a personality, which is the starting point of a person's way of thinking. Therefore, education must pay attention to this problem, so that children can develop good habits in this period, and then in Germany, wisdom, body, beauty, labor, these aspects of all-round development[1].

\section{The principles of moral education in preschool education}

\section{Set up "double link" consciousness}

The so-called "double class consciousness" is the combination of moral education outline and the outline of the two educational contents. Whether it is ethical education or subject education, it needs to be carried out in a mutually reinforcing environment. In this approach, it can realize the all-round development of children and realize the coordination and promotion of all aspects. Morality, intelligence, body, beauty and labor are the contents of a person's all-round progress. Whether it is sports, intelligence or character, it has an important impact on a child, especially moral education, which can help children to better understand society and understand society. To cultivate good behavior and quality and to emphasize the importance of moral, education is very beneficial to the development of children[2]. 
The content of education Dezhitimei overlap and penetration, such as sports on behalf of the health, it is the basis of other aspects of education, if the child is not healthy, it will affect its development in other areas. To realize the intellectual education for children, the emphasis is on the training of students' cognitive ability, which will affect their social morality and collective life. And aesthetic education influences children's cognition of the beautiful things around us. So, to achieve all-round progress, mutual penetration, mutual assistance. Only kindergarten education fully realizes the importance of these contents, and then can better realize the all-round development of children's physical and mental[3].

The formulation of ethical education outline for early childhood education meets the needs of the times. It has a certain integrity, and it is also a programmatic document to guide children's moral education. Every teacher is familiar with and apply it. For the various educational programs, it is based on the age characteristics of children, for all education, which takes into account the acceptance of children, it is in line with the progress of children themselves, but also the basis for education grams. If each preschool education workers are able to fully establish the "two classes" consciousness, so in the daily life, can carry out random sex education for children, some factors will be dominant and recessive are combined with each other, so you can make moral education truly implemented.

\section{The combination of school and family}

Kindergarten and family are important learning places for a child. After entering kindergarten, children should receive the kindergarten education, and they will also be influenced by some family factors. Children are a mirror of their parents, and their children's personality, character and hobbies are more or less influenced by their parents. Therefore, family education plays an important role in the education of a child. And kindergarten should also be classified according to the parents of changed circumstances. There are three main situations in the early childhood education. One is that parents do not pay attention to it, and that they are not good education. One is that although they pay attention to them, they do not know the way, and the other is not only paying attention to them. But also being good education. For parents of the former type, the kindergarten should strengthen ties with such groups, do ideological work for them, publicize and educate their importance, and pass on some correct methods and content. For additional types of parents, kindergarten should train their skills and methods. For the latter class of parents, teachers can organize them to introduce some successful experiences in educating their children, so as to achieve communication and sharing[4].

\section{The optimization strategy of moral education in preschool education}

\section{Encourage students to learn to express love}

Children are still in a lively and active age. They are weaker in cognition and self-discipline at this time, but they already have a certain sense of right and wrong. Therefore, it is a need for a good teacher-student relationship. Teachers should show their concern, love and respect to students in a timely manner, and create an atmosphere of relaxation and good communication for students. Excellent teacher-student relationship not only helps to communicate with each other, but also makes children more willing to accept education from teachers. Because the child itself has strong ability to imitate, so that teachers in the teaching process, must be timely to the students to express enough care, allowing students to imitate the teacher's approach to live together with others. In the process of getting along with and communicating with each other, teachers should further let students lay down their mental defenses and invite them to try to accept teachers. For example, some of the children at school, they all have the psychological conflict, this time to the kindergarten, the teachers can do some children of a kiss, a hug action, and can help children eliminate the strangeness of the environment and people[5].

\section{Develop good daily habits for children}

Childhood is an important stage of a student's children, students can get more knowledge in their daily learning, have more capacity, so the daily teaching must be innovative, to have a good learning effect, thus making the students comprehensive quality of children can be improved. Once the children're daily teaching innovation, students have the quality will be reflected. For children's 
everyday teaching, the so-called innovation mainly focuses on the individual innovation of students. For example, to train students' creative ability, the focus of this work is to train students' innovative awareness and spirit of exploration, so that students can use their existing knowledge to solve the problem. In this process, students can be independent and objective in their study, which will lay a good foundation for students' creativity. Daily life education is the most effective and direct way to many teaching methods, the so-called daily life education, is a teacher according to the age characteristics of students' actual situation, starting from the emotional education, further realize the penetration of the daily life of students, cultivate students' good learning habits, living habits from childhood. For example, in the process of washing, teachers should let students in line, cannot appear in the queue, after washing hands, let students turn off the tap, so that children can develop a habit of saving water. When eating, let children do, whether in bowls or on the table, should be kept clean, so that not only conducive to children to promote thrift habits, but also to further enhance their self-cultivation[6].

Through these subtle ways, children are further encouraged to develop in a good way. At the same time, let students learn to get along with classmates and teachers, for example, to greet each other and to be polite and good children. So, when you see some students greeting others, teachers should encourage them in a timely manner. If you see some students pushing each other situation, teachers are not eager to criticize the students. This will enable students to produce psychological resistance. You can use more encouragement and praise to guide students. Note that in the implementation of moral education in the process, we must pay attention to their own wording, and found that the child's flash point, mostly in the positive education, through the approach to guide the improvement of children's behavior. In the specific process of schooling, we should be good at discovering children's bright spots, so that children develop good study habits. Some children will own toys to play with other children, this time the teacher should encourage the child, let students understand that such behavior is correct, will be encouraged and supported, ability can further allow students to make a distinction between right and wrong.

\section{Keep abreast of students}

Infant teaching is closely connected with moral education. Teachers' behavior and attitude can directly influence the teaching of moral education. If the teacher is full of enthusiasm and vitality, and have a strong sense of responsibility, the students have confidence on the approved attitude, so in daily life, he will become the example of the students, which can exert a subtle influence on the ideological level of the students[7].

Teachers in sport activities, to act as knowledge and discipline to maintain, in this process, they need to look around, but sometimes ignore the observation on children's activity, it has strong randomness of guidance. Some teachers were not very careful, even know is also not comprehensive enough, don't even know what children think, do not know what the children want to do, but also do not understand and accept the current level of physical and mental characteristics of children, children playing there is supervision. In fact, early childhood education must be carried out to further read hastily and without thinking, but every student, understand every student in teaching, teachers should have a deeper understanding of their students, can start from the family situation, understand the development of children and the psychological characteristics, hobbies can also, from the interest of children, to establish a file for the. Teachers should communicate with their children regularly and pay attention to their children's situation and trends. Based on this, we should develop systematic and reasonable moral education goals for students, so as to urge more students to achieve good development. In the specific activities, the activities of teachers should pay attention to children's children, when difficulties arise when teachers have enough patience to explain to children, allow children to go wrong, let the children explore the use and operation, as far as possible to solve their own problems. Teachers should also pay attention to the role of games in the process of young children's exploration. Teachers cannot be impatient for success, but to observe and wait to find the child's characteristics. Give children more free space, encourage them to choose and make decisions, so that children can really become their own owners, the game cannot be due to rigid planning and lose its due soul. 


\section{To achieve home cooperation}

Schools and families should work together so that moral education can be also improved. The family is the child's first class, many children's habits are formed in the family, so the family should pay particular attention to the moral education of children, and guide children to develop good habits. Relying solely on the power of one's family or the school does not necessarily guarantee that moral education can be perfect. Only when family education and school education work together can we really carry out ethical education better. For example, in the process of education, teachers should actively communicate with parents, children can arrange a family mission, and then by the parents to supervise and cooperate, so as to further cultivate children's love of labor, to complete the task of independent personality.

\section{Enrich the content of moral education}

Moral education is not speaking generally, but should combine the many social resources together to complete. For example, in a particular day, teachers can design around a theme of moral education activities, such as in the "61" children's day, children in poor areas to communicate with others, learning and communication, cultivate children to care for others, care for others behavior. For example, to the "99 Chongyang Festival", you can encourage children to elaborate gifts, give grandparents, respect for the elderly schooling. Through a number of strong festive atmosphere and interesting forms of activities, to carry out a specific moral education, allowing children to learn more in a relaxed atmosphere of virtue. In addition, we can also contact the local culture and conduct moral education for our children. Local culture is closely related to the indigenous people's culture, through the study of local culture, to cultivate children's love for their hometown, while encouraging more home loving home and the motherland. Because various activities are carried out outdoors, in teaching activities, it is inevitable that such and such unexpected things will happen. This time, teachers can make a reasonable use of some unexpected events, carries on the moral education of the students, so not only can the events into the specific content of moral education, also give students leave a deeper impression[8].

\section{Conclusion}

In the moral education of children, there are two factors that cannot be ignored. One is the teacher. The other is the parent. Teachers' personality will affect the child's mode of thinking and outlook on life, and parental education will also affect the child's interpersonal attitude, so, how to proceed from the perspective of children's development, moral education can be carried out better in the young age of a child, it is essential to develop in an all-round way the children.

\section{References}

[1] Babkirk S, Saunders L V, Solomon B, et al. Executive Function and Temperamental Fear Concurrently Predict Deception in School-Aged Children[J]. Journal of Moral Education, 2015, 44(4):425.

[2]Puroila A M, Haho A. Moral Functioning: Navigating the Messy Landscape of Values in Finnish Preschools[J]. Scandinavian Journal of Educational Research, 2016:1-15.

[3]Liang J Y, Tan S, O’ Halloran K. Representing sexuality and morality in sex education picture books in contemporary China[J]. Social Semiotics, 2016:1-20.

[4]Ho W C. Moral Education in China's Music Education: Development and Challenges.[J]. International Journal of Music Education, 2010, 28(1):71-87.

[5]Riley S. Moral Identity and Moral Education: A Roycean Proposal for School Choice[J]. Pluralist, 2007, 2(2):91-105. 
[6]Shalom M. Fisch, Susan K. McCann Brown, David I. Cohen. Young Children's Comprehension of Educational Television: the Role of Visual Information and Intonation[J]. Media Psychology, 2001, 3(4):365-378.

[7]Shapiro S L, Lyons K E, Miller R C, et al. Contemplation in the Classroom: a New Direction for Improving Childhood Education[J]. Educational Psychology Review, 2015, 27(1):1-30.

[8]Hyemin Han. Lost in transition: the dark side of emerging adulthood[J]. Journal of Moral Education, 2012, 41(1):145-147. 